\title{
Political Bias and War
}

\section{By Matthew O. Jackson and Massimo Morelli*}

\begin{abstract}
We examine how countries' incentives to go to war depend on the "political bias" of their pivotal decision makers. This bias is measured by a decision maker's risk/ reward ratio from a war compared to that of the country at large. If there is no political bias, then there are mutually acceptable transfers from one country to the other that will avoid a war in the presence of commitment or enforceability of peace treaties. There are cases with a strong enough bias on the part of one or both countries where war cannot be prevented by any transfer payments. Our results shed some new light on the uneven contender paradox and the interpretation of the "democratic peace." We examine countries' choices of the bias of their leaders and show that when transfers are possible, at least one country will choose a biased leader, as that leads to a strong bargaining position and extraction of transfers. (JEL D72, D74)
\end{abstract}

The rich history of war provides evidence of its devastating consequences and of the wide variety of circumstances that lead to it. ${ }^{1}$ While there is much that we know about wars, there is still much to be learned about how the choice to go to war differs across countries and circumstances, and in particular how this relates to the interplay between economic circumstances and political regimes. Although religious and ethnic conflicts have played key roles in many wars, balance of power, territorial disputes, expansion of territory, and access to key resources or wealth are often either involved or the primary driving force behind wars. ${ }^{2}$ In this paper, we

\footnotetext{
* Jackson: Department of Economics, Stanford University, Stanford, CA 94305 (e-mail: jacksonm@stanford.edu); Morelli: Department of Economics and Department of Political Science, The Ohio State University, Columbus, OH 43210 (e-mail: morelli.10@osu.edu). We are grateful for financial support from the National Science Foundation under grants SES-0316493 and SES-0519205, the Guggenheim Foundation, and the Center for Advanced Studies in Behavioral Sciences. We thank M. Battaglini, V. Crawford, J. Eguia, J. Fearon, G. Gatta, D. Jankowski, T. Kim, L. Mathevet, R. Powell, E. Rasmusen, G. Tabellini, D. Verdier, C. Volden, L. Zambernardi, and three anonymous referees for helpful comments, and participants at seminars for useful feedback.

${ }^{1}$ See, for example, Geoffrey Blainey (1973) and David Kaiser (1990)

${ }^{2}$ Resources and wealth are the focus of much of the recent formal literature on war, as discussed below. Moreover, materialistic motivations have been identified as primary source of wars in the history of empires (see, for example, William V. Harris 1979 and Ronald Findlay 1996), and some scholars argue that modernization has
}

build a model that serves as a basis for understanding how political structure (crudely modeled) interacts with economic incentives to determine when wars occur.

Our model of war is described as follows. Two countries are faced with a possible war, and each knows their respective probability of winning, which depends on their respective wealth levels. If a war ensues, each country incurs a cost and then the victor claims a portion of the loser's wealth. The incentives of each country thus depend on the costs, the potential spoils, and the probability that each will win. If either country wishes to go to war, then war ensues. Countries can offer to give (or receive) a transfer in order to avoid a war.

The way in which we tie the analysis back to political structure is crude but powerful. We model a country's decisions through the eyes of the pivotal decision maker in the society. For instance, this could be an executive, a monarch, the median member of an oligarchy, or the median voter, depending on the political regime. The ratio of share of benefits from war

\footnotetext{
further increased the profitability of conquest (see Peter Liberman 1993, who discusses Hitler's exploitation of occupied territories during World War II). A recent example of a war related to materialistic expansion motivations is the invasion of Kuwait in 1990. We stress that by materialistic motivations we include power and control motivations of country leaders, and hence our arguments apply even when no territory or resource is a cause of war.
} 
compared to share of costs for this pivotal agent is thus a critical determinant of a country's decisions. We call this ratio "political bias." If it is close to one, then the country's critical decision maker's relative benefits/costs are similar to the country at large. If this ratio is greater than one, then we say that the country leader has a "positive bias." An unbiased leader is "representative" of the interests of the country, in the sense that he or she sees the same relative benefits and costs from a war as the country does as a whole. Hence, absence of bias may be seen as an operationalization of a representativeness property associated with the level of democracy of a political regime. ${ }^{3}$

Political bias essentially embodies anything that might lead to different incentives for the critical decision maker relative to the society as a whole. For instance, in an authoritarian regime, it may be that a leader can keep a disproportionate share of the gains from a war. It may also be that the leader sees other gains from war, in personal recognition or power. Similarly, if the military is leading a country, then it may be that military leaders gain disproportionately from war in terms of accumulated power, or even in keeping their troops occupied. These effects are not unique to autocratic or oligarchic regimes, but can also occur in democracies. ${ }^{4}$ Sometimes a leader knows that (s)he is more easily reelected if the country is at war at the time of the elections, or may have other indirect benefits in terms of benefiting friends or companies to which he or she has ties. It is also important to note that bias can also go in the other direction. For instance, if a democratic leader risks losing office if a war is lost, then that might lead him or her to overweight the costs of war relative to

\footnotetext{
${ }^{3}$ To the extent that a democracy is embodied by the median voter, this then embodies the relative distribution of the costs and benefits of a war across the population, where things like relative tax rates can be influential.

${ }^{4}$ An argument in favor of the hypothesis that democracies tend to be less biased can be found in David A. Lake (1992): "State rent seeking creates an imperialist bias in a country's foreign policy. This bias is smallest in democracies, where the costs to society of controlling the State are relatively low, and greatest in autocracies, where the costs are higher."
}

gains, resulting in a bias factor of less than one. ${ }^{5,6}$ In general, political bias reflects the different cost/benefit calculation of the agent (the leader or pivotal decision maker in the government) who bargains on behalf of the principal (the country). This agency problem can determine conflict, even when countries have accurate intelligence about each other's military capabilities, and even when they have the power to bargain and make transfers to avoid a war.

We show that if both countries have unbiased leaders, then war can be avoided, provided the countries can make transfers and provided they can commit to peace conditional on receiving transfers. If either country has a leader with positive bias, however, then war can ensue, and whether it does depends on the specifics of the war technology, relative wealth, potential costs and spoils of war, and the size of the biases. We also study such bargaining when neither country can commit to peace after receiving transfers. ${ }^{7}$ In that case, the incentives are more complicated, as it must be that after receiving a transfer, a war would no longer be worthwhile for the potential aggressor. ${ }^{8}$ When peace treaties are not

\footnotetext{
${ }^{5}$ For an analysis of the political costs of war for different regimes, see Bruce Bueno de Mesquita and Randolph M. Siverson (1995) and Giacomo Chiozza and Hein E. Goemans (2004) .

${ }^{6}$ See George W. Downs and David M. Rocke (1994) and Ahmer Tarar (2006) for different discussions of the incentives of an executive to engage in war relative to the electorate's incentives to retain the executive.

7 This commitment problem is usually studied in dynamic models. For example, in Michael A. Schwarz and Konstantin Sonin (2004) war can be avoided with a continuous stream of transfers that comes at a fast enough rate to always have the aggressor wish to delay rather than attack. Along similar lines, James Fearon (1996) shows that as long as commitment not to go to war after receiving a transfer exists for one period, the long-run commitment can be brought back in, through an appropriate dynamic mechanism. In our no-commitment model, a transfer doesn't bind the actions of the receiver for any length of time, and hence those results do not apply.

${ }^{8}$ Given that the attention of empirical studies and historians has largely been on wars and armed conflicts that actually occurred, it is difficult to find direct empirical evidence of transfers that avoided a war, for the obvious counterfactual reasons. Nevertheless, one can certainly see the role of transfers in many epochs. By transfers we do not refer to explicit monetary transfers only; we refer also to transfers of territory, control over seas, and even implicit transfers of wealth and control linked to the marriages between royal families across Europe up to the end of the nineteenth century. In the eighteenth and nineteenth
} 
enforceable, even two countries with unbiased leaders (or, in short, unbiased countries) may go to war, depending on the sensitivity of the probability of winning to the difference in power.

Our model suggests some novel considerations regarding the so-called "Democratic Peace" (or "Liberal Peace") observation, where two democracies are much less likely to go to war with each other than are two countries when at least one is not a democracy (see, e.g., Michael W. Doyle 1986 and Bruce Russett 1993). We show that, at most, one of two unbiased countries will want to go to war, and if binding treaties can be written, then two unbiased countries can always reach an agreement over transfers that will avoid a war. We can call this unbiased peace, and it can be interpreted as a new explanation of the democratic peace observation under the hypothesis that democracies tend to be less biased than nondemocratic regimes. ${ }^{9}$ Wars between democracies are avoided not due to similarity of norms or cultural affinities, but due to a lack of political bias in the bargaining process (determined perhaps by the system of checks and balances typical of a democracy). Our model does predict that two politically biased democracies could still go to war with each other if they are each sufficiently biased. Thus, mutual democracy is neither a necessary nor sufficient condition for peace.

centuries there was an explicit system of compensations among European great powers: the first (1772) and the third (1795) partition of Poland, the Franco-British and RussoBritish negotiations prior to the formation of the Entente Cordiale, as well as the resolutions of the Near Eastern crises of 1875-1877 and 1885-1888. Trade concessions or replacements of ministers could be indirect forms of transfers to the threatening power as well. The most important principle in UN Security Council resolution 242 was "land for peace," and such a principle was used as the basis for Israel's peace treaty with Egypt in 1979, and was at the center of the Oslo Accords with the PLO. Another example is the provision of iron and logistical support by Sweden to Hitler in World War II. A notable example of failure of appeasement due to a lack of commitment is the Munich Agreement of 1938.

${ }^{9}$ The idea that incentives of aristocrats to go to war might differ from those of democratic leaders is not new, and is well articulated in Immanuel Kant (1795). The novelty here is in explicitly modeling bias in a model where we can understand its role in bargaining to avoid war, and its interaction with commitment and the technology of war, as well as a country's incentives to select its leaders and their bias.
Using political bias as the key driver of war, and assuming a negative correlation between political bias and the level of democracy, our model provides an explanation of the stylized fact that democracies tend to win wars against autocracies: ceteris paribus, more biased leaders are willing to enter conflicts that they have a lower probability of winning (see David A. Lake 1992 for a related argument). Another stylized fact (see Clifton Morgan and Sally H. Campbell 1991) that our model can explain relates to the effect of the size of a democracy on its incentives to go to war versus bargaining, depending on the sensitivity of the probability of winning to the difference in wealth between contenders. ${ }^{10}$

Another phenomenon on which our model can shed light is the so-called uneven contenders paradox, first discussed by Carl von Clausewitz (1832), which refers to situations in which one small or weak country doesn't concede or is the initiator of conflict, even though it expects losses from a war. In our model, the weaker country can in fact be the aggressor because of the leader's bias and/or because the probability of winning, or war technology, ${ }^{11}$ is not very sensitive to the difference in power between the contenders. In other words, "who attacks whom" depends not only on relative wealths but, crucially, also on their relative bias and on the technology of war.

The sensitivity of war technology is shown to be one of the key determinants of the incentives to form coalitions as well: when the war technology is not too sensitive to power differences, there are no incentives to form alliances, defensive or offensive, whereas when the war technology is very sensitive, there can be incentives to form offensive alliances and/or defensive alliances, depending on the distribution of wealth.

\footnotetext{
${ }^{10}$ Given that the model aims to isolate and highlight the effect of bias and does not include other important domestic characteristics of different political regimes, there are other observations on democratic peace (see, e.g., Bueno De Mesquita et al. 1999) that cannot be explained with our simple model. For example, since we do not analyze strategic timing issues, the model cannot explain why democracies seem to be more likely to initiate wars against autocracies than vice versa.

${ }^{11}$ Jack Hirshleifer (1989) was the first to call the probability of winning in a contest the "technology of conflict." We believe this terminology is appropriate since the sensitivity of the probability of winning to the relative positions of the contenders is mostly influenced by military technology.
} 
A strong form of stability, where no group of countries could gain by reorganizing themselves into new alliances, will generally not be attainable in this case of sensitive war technology. This is related to issues of empty-cores in a variety of coalitional games with some sort of competition. In settings where core-stability fails, it makes sense to explore weaker forms of stability. ${ }^{12}$ We show that it is possible to sustain large alliances of countries.

We also examine the incentives of citizens to (s)elect leaders of different biases. In the absence of transfers, a country would prefer to have an unbiased leader. On the other hand, when transfers are available, a country may benefit from having a biased leader who extracts transfers from other countries, provided the bias is not so strong to lead the country into undesired wars. Examining equilibrium choices of bias of two countries, we see that at least one country chooses a biased leader and there can be multiple such equilibria. Once we introduce uncertainty regarding the opponent's wealth and power at the time of the choice of leaders, war can occur in equilibrium.

To clarify the connection of this paper with the existing rational choice literature in international relations, note that in any "realist" framework (a term due to von Clausewitz 1832), war is based on practical cost/benefit calculations and with full knowledge of circumstances. As an example of rational realist model, Bruce Bueno de Mesquita (1981) studies war as based on cost/ benefit calculations by countries (interpreted as unitary actors). In such models, if one allows for bargaining and transfers, war should not be possible, whereas in our model the agency problem identified by the presence of political bias breaks the unitary actor assumption and allows for novel explanations of war.

\footnotetext{
${ }^{12}$ Another possibility is to appeal to such other predictions about outcomes as von Neumann-Morgenstern stable sets, as in James Jordan (2006), who studies pillage games (those are coalitional games in which a coalition with more wealth than another can make the other surrender all or part of its wealth at no cost). Pillage is clearly related to war, but differs in that it is costless and the outcome is certain (the stronger takes from the weaker). See also Michel Piccione and Ariel Rubinstein (2004), who examine distributions of resources across countries so that no country has any incentive to take from another, where stronger countries can take costlessly and at will from weaker countries.
}

Bueno de Mesquita et al. (2003) analyze the variation across countries in terms of the necessary support for a leader within the so-called "selectorate." In their model, democratic leaders need a larger coalition to support them relative to nondemocratic leaders. Keeping a larger coalition satisfied is more costly, and hence losing a war is relatively more costly for democratic leaders, and generally makes them less prone to war. Thus, beside the fact that Bueno de Mesquita et al. (2003) do not analyze transfers, their theory is based on a political leader maintaining an "internal" base, while ours is a complementary theory that focuses on political bias with respect to "external" bargaining.

In our model it is possible for two countries to go to war even though they both have complete information about the relative likelihood of winning, and despite the fact that they could bargain and make payments to avoid war and that war burns resources. This is related to the "Hicks Paradox" from the bargaining literature which ponders the occurrence of strikes and failed bargaining in general contexts. Since our model of war operates under complete information, it is complementary to models based on asymmetric information and differences in beliefs. ${ }^{13}$ Other complementary potential causes of war identified in the literature include the presence of indivisibilities in bargaining (see Jonathan Kirshner 2000), strategic timing considerations (summarized, e.g., in James Fearon 1995), and "spiral theories" of war (see, e.g., Kenneth Waltz 1959, Thomas A. Schelling 1963, Robert Jervis 1976, 1978, and, more recently, Sandeep Baliga and Tomas Sjöström 2004). In John F. Nash (1953), Schelling (1966), and Vincent P. Crawford (1982), bargaining can break down because of excessive demands or excessive commitments to fight made during the bargaining process, whereas in our model bargaining would not break down if the biases are not too high. Thus, in our model the source of ex post conflict is in

\footnotetext{
${ }^{13}$ Explanations of wars based on miscalculations or errors due to lack of information or to different priors about relative power have been discussed by Blainey (1973), Erik A. Gartzke (1999), and R. Harrison Wagner (2000), among others. As argued by Fearon $(1995,1997)$, once we allow for bargaining and communication, these explanations are consistent if there are strategic incentives to hide (or not to reveal) information or problems with signalling.
} 
the excessively aggressive agents chosen by the principal selectorates. The source of bargaining failure in our model is therefore more closely related to delegation games (Chaim Fershtman and Kenneth L. Judd 1987) such as that of Stephen R. G. Jones (1989), where there is an explicit combination of agency and bargaining problems. ${ }^{14}$

\section{A Materialistic Model of War}

We first focus on a potential war between two countries in complete isolation. We denote the countries by $i$ and $j$. We return to the case of more countries below.

Let $w_{i}$ denote the total wealth of country $i$.

We model the technology of war in a simple way. If countries $i$ and $j$ go to war against each other, country $i$ prevails with probability $p_{i}\left(w_{i}, w_{j}\right)$, which is nondecreasing in $w_{i}$ and nonincreasing in $w_{j}{ }^{15}$ When the wealth levels are clear, we let $p_{i j}$ denote $p_{i}\left(w_{i}, w_{j}\right)$. The probability that country $i$ prevails is $p_{j i}=1-p_{i j}$. This simple form ignores the possibility of a stalemate or any gradation of outcome, but still captures the essence of war necessary to understand the incentives to go to war. Note that it is possible that $p_{i}\left(w_{i}, w_{j}\right) \neq 1 / 2$ when $w_{i}=w_{j}$. This allows $i$, for instance, to have some geographic, population, or technological advantage or disadvantage.

In terms of the consequences of a war, we model the costs and benefits as follows. Regardless of winning or losing, a war costs a country a fraction $C>0$ of its wealth. If a country wins, then it gains a fraction $G>0$ of the other country's wealth. ${ }^{16}$ So, after a war against country $j$, country $i$ 's wealth is $w_{i}(1-C-G)$

\footnotetext{
${ }^{14}$ In contrast to our model, however, in Jones (1989) the choice of agents by the two principals in the first stage does not affect the disagreement point or possible agreements of the second-stage bargaining problem. In our model, the disagreement utility (war payoffs) and the potential transfers are affected by the biases, and so by choosing the biases the countries are changing the key elements of the subsequent bargaining game.

${ }^{15}$ For empirical support of the hypothesis that the probability of winning depends on the relative wealth levels (supposing that relative wealth levels determine relative levels of war mobilization), see Mark Harrison (2005) and Charles Tilly (1992).

16 We could also add fixed costs and/or benefits. However, adding such parameters would add little to the
}

if it loses and $w_{i}(1-C)+G w_{j}$ if it wins. We let $C+G \leq 1$, so that at most the full wealth of a country can be lost to the cost of war and the other country.

When two countries meet, they each decide whether to go to war, and if either decides to go to war then a war occurs. As part of the decision process they may be able to make transfers of resources or territory, or to make other concessions.

Let $a_{j}$ denote the fraction of $w_{j}$ controlled by the agent who is pivotal in the decisions of country $j$. The fraction of the spoils of war that the pivotal agent might control can differ from the fraction of the wealth that they hold, especially in nondemocratic regimes or in situations where there might be other sorts of benefits from war (for instance, to a pivotal military leader). The fraction of the spoils of war obtained by the pivotal agent is $a_{j}^{\prime}$. Thus, in the absence of any transfers, the pivotal agent of a country $j$ wishes to go to war if and only if ${ }^{17}$

$$
\begin{aligned}
& (1-C) a_{j} w_{j}-\left(1-p_{j i}\right) G a_{j} w_{j}+p_{j i} G a_{j}^{\prime} w_{i} \\
& \quad>a_{j} w_{j},
\end{aligned}
$$

where the left-hand side is the expected value of a war and the right-hand side is the expected value of not going to war.

We can rewrite this so that the expected gains are on the left-hand side and the expected losses are on the right-hand side:

$$
p_{j i} G a_{j}^{\prime} w_{i}>\left[C+\left(1-p_{j i}\right) G\right] a_{j} w_{j} .
$$

\section{A. Political Bias}

Let $B_{j}=a_{j}^{\prime} / a_{j}$ denote the ratio of the percentage that the pivotal decision-making agent

qualitative analysis of the interaction of political bias and war incentives.

${ }^{17}$ We examine this as if the other country were choosing not to go to war. Although this could turn out to be a hypothetical comparison, it is still the relevant one, as the equilibrium outcome (in the absence of transfers) would be that the countries end up going to war if and only if the inequality holds for at least one of the two countries' leaders. 
stands to gain versus what he or she has at risk. We call this the political bias of country $j$.

It is important to emphasize that although we model the relative gains and losses as being proportional to wealth, the critical aspect of political bias in our model is that there is a difference between the incentives of the pivotal decision maker and the country as a whole. This might, more generally, include things like potential power that a military leader or politician might gain from winning a war, which would bias them away from considering the pure costs and gains from war and can effectively be viewed as a distorted view of gains $\left(a_{j}^{\prime}>a_{j}\right)$. We also note that bias could similarly be less than 1 . It could be, for instance, that a politician fears losing office due to a lost war, and this could manifest itself in having the politician overweight the losses of a war.

We can rewrite (2) as:

$$
B_{j} p_{j i} G w_{i}>\left[C+\left(1-p_{j i}\right) G\right] w_{j} .
$$

This inequality, where the left-hand side is the normalized expected gains (having divided by $a_{j}$ ) and the right-hand side is the normalized expected costs, makes the role of the bias quite clear. If $B_{j}>1$, then the leader overweights potential gains (since in this case the rest of the country has a ratio at stake $\left(1-a_{j}^{\prime}\right) /\left(1-a_{j}\right)$ $<1$ ); while if it is less than 1 , it underweights potential gains.

We note some intuitive comparative statics.

The "tendency" of $j$ to want to go to war (as measured in the range of parameter values where $j$ wants to go to war):

- Is increasing in $B_{j}$ and $G$, and decreasing in $C$;

- Depends only on the ratio of $C / G$ and not on the absolute levels of either $C$ or $G$ : and

- Depends only on $B_{j}$ and not on the absolute levels of either $a_{j}$ or $a_{j}^{\prime}$.

These show the intuitive comparative statics that a larger bias makes a country more prone to war, as does an increase in the ratio of benefits to costs of war. The effects of the wealth levels, $w_{i}$ and $w_{j}$, are ambiguous, as they enter through $p_{j i}$, as well as directly. For instance, as $w_{i}$ increases, the potential spoils from war increase, but the probability of winning for $j$ decreases. Which of these two effects dominates depends on the technology of war.

Given this dependence on the technology, for the purposes of illustration it is useful to carry several examples of winning probabilities throughout.

Example 1. Proportional Probability of Winning: We say that the probability of winning is proportional (to relative wealths) if $p_{j i}=w_{j} /\left(w_{j}+\right.$ $\left.w_{i}\right)$.

In this case, (3) can be rewritten as

$$
\frac{\left(B_{j}-1\right) G w_{i}}{w_{i}+w_{j}}>C .
$$

REMARK 1: Under a proportional probability of winning, a politically unbiased country never wishes to go to war. If $B_{j}>1$, then the tendency for $j$ to want to go to war is increasing in $w_{i}$ and decreasing in $w_{j}$.

Example 2. Fixed Probability of Winning: We say that the probability of winning a war is fixed if $p_{j i}=1 / 2$, regardless of wealth levels. This is an extreme case of situations in which wealth has no impact on the probability of winning a war.

In that case, (3) can be rewritten as

$$
B \frac{w_{i}}{w_{j}}>1+\frac{2 C}{G} .
$$

Here, an unbiased country could want to go to war, but only if its wealth is low compared to the other country. In general, in this case a country's tendency to want to go to war is higher if it has relatively less wealth.

Example 3. Higher Wealth Wins: We say that the higher wealth wins if $p_{j i}=1$ when $w_{j}>w_{i}$, $p_{j i}=0$ when $w_{j}<w_{i}$, and $p_{j i}=1 / 2$ when $w_{j}=w_{i}$. This is another extreme case that captures situations in which wealth is the critical determinant of the probability of winning a war.

In this case, a country $j$ wishes to go to war (in the absence of transfers) whenever $w_{j}>w_{i}$ and gains outweigh losses, $B_{j} G w_{i}>C w_{j}$. When wealths are equal, the expected gains-versuslosses condition is as in the fixed case. 
Example 2 and Example 3 will also be referred to, respectively, as the extremely insensitive and extremely sensitive war technologies.

\section{The Interplay between Political Bias and Transfers}

We begin with the important benchmark where no transfers are possible.

\section{A. War Incentives in the Absence of Transfers}

When two countries meet, it could be that neither country wishes to go to war, just one country wishes to go to war, or both countries wish to go to war. If neither wishes it, then clearly there is no war, and transfers would be irrelevant. If both countries wish war, then there is a war and no transfers could possibly avoid it. The only situation where one country might be willing to make transfers that could induce the other country to avoid a war comes when only one country has an interest in engaging in war. Let us first make some observations regarding the parameters that lead to the various possible scenarios, and then come back to focus on transfers.

PROPOSITION 1 (No Transfers): Consider any fixed $w_{i}, w_{j}$, and $p_{i j}$.

(i) If $B_{i}=B_{j}=1$, then at most one country wishes to go to war regardless of the other parameters.

(ii) Fixing any ratio $C / G$, if $B_{i}$ and $B_{j}$ are both sufficiently large, then both countries wish to go to war.

(iii) Fixing any $B_{i}$ and $B_{j}$, if $C / G$ is large enough, then neither country wishes to go to war.

PROOF:

See the Appendix.

For fixed biases $B_{i}>1, B_{j}>1$, and a fixed ratio $C / G$, whether or not one or both countries wish to go to war depends on the technology $p_{i}(\cdot, \cdot)$ and the wealth levels in ways that may not be purely monotone.

\section{B. Transfers to Avoid a War: The Commitment Case}

We now consider situations where in the absence of any transfers one country would like to go to war but the other would not, and characterize when it is that transfers avoid a war.

We start with the case where countries can commit to peace conditional on the transfer. This is a situation where the countries can sign some (internationally) enforceable treaty so that they will not go to war conditional on the transfer. In the absence of such enforceability or commitment, it could be that $i$ makes the transfer to $j$ and then $j$ invades anyway. We deal with the case of no commitment in the next section.

Commitment could come from international organizations to the extent that they have threats and promises to help enforce peace agreements (e.g., the United Nations), or, alternatively, from longer-term reputation effects. If a country is to face a number of countries over time, then by abiding by its promises it will earn future transfers, while otherwise it will end up fighting a series of wars. Clearly, if transfers are preferable to war in each case, then the country would prefer to have a series of transfers to a series of wars. ${ }^{18}$

When transfers are made from country $i$ to country $j$, we assume that the decision maker in country $j$ gets $a_{j}^{\prime}$ of the transfer, and the decision maker in country $i$ loses $a_{i}$ of the transfer. Thus, decision makers' biases toward transfers are the same as those toward gains and losses from war. This is not critical to any of the results, as it is important only that a bias be present somewhere. We make this assumption to be consistent with gains and losses. ${ }^{19}$

The aim is to identify when it is that transfers will avoid a war. That is, we would like to know when is it that:

\footnotetext{
${ }^{18}$ We note that the commitment case also embodies no change in leaders (or their biases) over time, or at least some continuity in their incentives. To the extent that democracies change leaders frequently, one can at least imagine there being a problem of a new leader abiding by old agreements. However, that can be alleviated by reputation effects.

${ }^{19}$ For instance, our results still hold qualitatively (with some differences in the exact equations), if we assume that decision makers evaluate all transfers (in or out) at a rate of $a_{j}\left(\right.$ or all at $\left.a_{j}^{\prime}\right)$.
} 
- In the absence of transfers, $j$ wants to go to war with $i$;

- $i$ prefers to pay $t_{i j}>0$ to $j$ rather than going to war; and

- $j$ would prefer to have peace and the transfer $t_{i j}$ to going to war.

It is important to note that when we say that transfers avoid a war, we are imposing the constraint that a war would have occurred in the absence of any transfers.

As we show in the Appendix, the following condition characterizes the situations where transfers avoid a war:

$$
\begin{gathered}
p_{j i}\left(1+B_{j} \frac{w_{i}}{w_{j}}\right)-1>\frac{C}{G}> \\
\frac{\left(1-p_{j i}\right)\left(B_{i} B_{j}-1\right)}{\left(1+B_{j} \frac{w_{i}}{w_{j}}\right)},
\end{gathered}
$$

The left-hand side corresponds to country $j$ wanting to go to war in the absence of any transfers, while the right-hand side corresponds to the willingness of $i$ to make a transfer that would induce $j$ to no longer want to go to war. Based on this set of inequalities, we conclude the following.

PROPOSITION 2: Consider a case where $j$ wishes to go to war (in the absence of any transfers) while $i$ does not. Holding all else equal, the range of relative costs to gains, $C / G$, where a transfer can be made that will avoid a war, increases (in the sense of set inclusion) when

- $B_{i}$ decreases,

- $p_{j i}$ increases, and

- $w_{i} / w_{j}$ increases (holding $p_{j i}$ fixed). ${ }^{20}$

PROOF:

See the Appendix.

The proposition is fairly intuitive. Reducing $B_{i}$ makes $i$ less likely to want to go to war, and to gain less from a war, and hence willing to

\footnotetext{
${ }^{20}$ If we do not hold $p_{j i}$ fixed, then things are ambiguous, as larger relative wealth makes $i$ better able to pay, but also better able to win.
}

make larger transfers to avoid it. Increasing $p_{j i}$ or $w_{i} / w_{j}$ (holding $p_{j i}$ fixed) has the same effect, and also increases the range where $j$ would like to go to war in the absence of any transfers. So, for instance, a technological change that exogenously favors one country in a war (an increase in $p_{j i}$ ) makes transfers more likely to avoid war, especially when the challenger is more politically biased and/or poorer. ${ }^{21}$ It is important to note that it need not be the wealthier country that is the challenger. A poor but politically biased country can extract transfers.

The effect of the political bias of the potential attacking country $j, B_{j}$, is ambiguous. It makes country $j$ more aggressive, but also leads $i$ to be willing to make larger transfers. Which effect dominates depends on a variety of factors.

To illustrate the proposition, we consider the extreme benchmark cases. In the benchmark case where $p_{j i}=1 / 2$ regardless of wealth levels (Example 2), (6) implies that there exists a range of values of $C / G$ such that transfers help avoid war if and only if

$$
B_{i}<B_{j}\left(\frac{w_{i}}{w_{j}}\right)^{2} .
$$

So in this case it is very clear that transfers help the most when $B_{i}$ is small, $B_{j}$ is large, and/or $w_{i} / w_{j}$ is large. These correspond to situations where the transferring country is less biased, the aggressor is more biased, and the wealth at risk for the transferring country relative to the aggressor is larger. In the other extreme case where the higher wealth wins (Example 3), and when $j$ has a relative wealth advantage, (6) simplifies to

$$
B_{j} \frac{w_{i}}{w_{j}}>\frac{C}{G}>0 .
$$

Here, war is again "more avoidable" with larger bias $B_{j}$ and larger $w_{i} / w_{j}$ (which leads to larger

\footnotetext{
${ }^{21}$ Note that this description is consistent with some interpretations of the behavior of the dictator of North Korea (even though there is also a security concern): the biased leader of a poor country with access to a potential jump in the probability of winning a war with a neighbor may obtain transfers from other countries. Such transfers may depend on whether commitment problems can be overcome, something that we come back to below.
} 
relative transfers), but now $B_{i}$ is irrelevant as $i$ is sure to lose.

In the case of two unbiased countries, we obtain the following result.

PROPOSITION 3 (Unbiased Peace): Two unbiased countries $\left(B_{i}=B_{j}=1\right)$ will never go to war if they can make transfers to each other and the receiver of a transfer can commit not to go to war after receiving the transfer.

\section{PROOF:}

See the Appendix.

The result is easy to understand. War imposes costs, and so when bargaining is unbiased, the total pie from avoiding a war is larger than the total pie from going to war. Thus, transfers avoid a war. The formal proof comes from noting that the right-hand side of (6) becomes 0 when $B_{i}=B_{j}=1$, so one country is always willing to buy the other off. Thus, either war is avoided because neither wanted it in the first place, or because one country is willing to pay the other off (recalling that at most one unbiased country ever wants to go to war).

Proposition 3 identifies a new explanation for the observation that democracies rarely go to war with one another. Most of the explanations of this fact in the literature concern internal checks and balances within a democracy, or the cultural norms and relative affinities that one democracy has for another. Here we point out that two unbiased countries (and hence two democracies to the extent that they have smaller biases than dictatorships, at least on average) never go to war because they can always find some transfer (perhaps bargaining under the threat of war) that makes it irrational to go to war.

It is important to note that this conclusion is true only for two politically unbiased countries and is not true if either country is politically biased. Also, this further makes the point that it is not democracy that is the key determinant of peace, but absence of political bias.

\section{The No-Commitment Case}

Let us now consider situations where a country cannot commit to avoid a war if it receives transfers. As discussed above, commitment is related to a number of factors: the presence or lack of international organizations that have the ability and incentives to enforce agreements, the patience of the challenger, the likelihood of meeting other countries in the future from which the challenger might gain from having maintained a reputation for abiding by its agreements, etc. So, a lack of commitment power can stem from an absence of such institutions or dynamic incentives.

In the no-commitment case, in order to avoid a war, not only does a transfer have to be such that the potential aggressor is willing to forego the current opportunity for a war, but it also needs to be such that after the transfer has been made a war is no longer in the aggressor's interest. ${ }^{22}$ Transfers do three things:

- They make the target poorer and less appealing;

- They make the challenger richer, with more to lose; and

- They increase the probability that the challenger will win.

Here, we can see that there are countervailing effects. If the probability is not affected too much by a transfer, then it is possible for transfers to avoid a war, as transfers can change the wealth of the two countries so as to make it no longer in one country's interest to invade the other.

There are a number of things that we observe about the no-commitment case. First, we can show that the situations where war is avoided due to transfers in the case of no commitment are a strict subset of those when there is commitment. In both cases, the transfers that the potential target country is willing to make are the same. The only differences are from the challenger's perspective. The difference between the two

\footnotetext{
${ }^{22}$ This contrasts with a model by Fearon (1996), where a country can avoid a war by buying the other country off over time, and war never occurs. However, in Fearon's model, by accepting an offer today the other side commits to waiting a period before attacking. That is, they cannot simply take the transfer and then fight immediately. Then the next period they can bargain again, and so forth. So, a small amount of commitment (to delay a period) allows the full impact commitment back in. In our model, we require that immediately after the transfer is made a country not want to turn around and attack.
} 
cases is that in the commitment case, a potential aggressor compares the value of no war (their wealth plus any transfers) to what they would gain from a war in the absence of any transfers; while in the no-commitment case a potential aggressor compares the value of no war (again, their wealth plus any transfers) to what they would gain from a war after transfers have been made. The value of a war to an aggressor after it has received transfers is strictly higher than the value of a war before any transfers, as the probability of winning is weakly higher and, in the case where transfers have already been made, the aggressor gets to keep a portion of those transfers regardless of whether it wins or loses, while in the other case they get that wealth only if they win.

Next, the no-commitment case has the following interesting feature. There are situations in which some transfers, $t_{i j}>0$, would not avoid a war, yet there are lower transfers, $t_{i j}^{\prime}$, where $t_{i j}>t_{i j}^{\prime}>0$, which would avoid a war. Thus, it is possible that too high a transfer will lead to war while a lower transfer will avoid a war. This can be true in a case where the changes in transfers lead to substantial enough differences in the probability that the challenger wins the war. Larger transfers can lead the country making the transfers to be more vulnerable in terms of being more likely to lose a war, and thus higher transfers can end up leading to a war that lower transfers might have averted. This is illustrated in the following example.

First, we note that a transfer $t_{i j}$ from country $i$ to $j$ creates a situation in which $j$ does not want to go to war after having received the transfer in the case of no commitment, if ${ }^{23}$

$$
\begin{aligned}
& p_{j i}^{\prime} B_{j} G\left(w_{i}-t_{i j}\right) \\
& \quad \leq\left(C+\left(1-p_{j i}^{\prime}\right) G\right)\left(w_{j}+B_{j} t_{i j}\right),
\end{aligned}
$$

where $p_{j i}^{\prime}=p_{j i}\left(w_{j}+t_{i j}, w_{i}-t_{i j}\right)$.

Example 4. Smaller Transfers Avoid a War: Let $B_{i}=1, B_{j}=4, w_{i}=w_{j}=100, C=1 / 10, G=$ $1 / 10$, and $p_{i j}(w, w)=1 / 2$.

\footnotetext{
${ }^{23}$ This is simply a rewriting of (3) where $i$ 's wealth is $w_{i}-t_{i j}$, and where $j$ 's wealth from the biased decision maker's perspective is $w_{j}+B_{j} t_{i j}$, but enters into the war technology as $w_{j}+t_{i j}$.
}

Note that in this case (3) is satisfied, so initially $j$ wishes to go to war with $i$.

We estimate (see (14) in the Appendix) that $i$ would be willing to make a maximal transfer of $\bar{t}_{i j}=10$ to avoid war. In the case of commitment, we can then check that this would avoid war (see (12) in the appendix, which is then satisfied).

Suppose that $p_{j i}(110,90)=3 / 4$. Thus, if a transfer of $\bar{t}_{i j}=10$ is made, then $j$ would still wish to go to war after the transfer, as (7) is not satisfied, and so the transfer would not avoid a war.

Consider, however, a smaller transfer of $t=8$. Suppose that $p_{j i}(108,92)=1 / 2+\varepsilon$. For small enough $\varepsilon,(7)$ is satisfied and so this smaller $t$ avoids a war.

While the specific numbers in the example may seem contrived, it is not a knife-edge case. Moreover, this shows that we cannot adopt the method used to prove results in the last section, where we deduce the maximal possible transfer that a country is willing to make to avoid a war and see if that avoids a war. Without specifying the $p$ function, one cannot determine which transfers will avoid a war.

What we do know is that:

- The set of parameter values where transfers avoid a war is a subset of the commitment case;

- The set of parameters for which war is avoided grows as $C / G$ increases; and

- The set of parameters for which war is avoided grows as $B_{i}$ decreases.

The fact that smaller $B_{i}$ helps avoid war is due to the fact that this results in an increase in the set of transfers that $i$ is willing to make. The effect of $C / G$ increasing is clear, as it helps make both countries wish to avoid a war. The effects of $B_{j}$ and $w_{i}, w_{j}$ are ambiguous, as again the technology of war $\left(p_{j i}\right)$ matters.

There are cases where we can deduce things about the ability of transfers to avoid war. The key to Example 4 is that there is a large change in probability due to a larger transfer, so there is a (local) convexity of the probability of winning function. If the probability function is not affected at all, as in Example 2, or is proportional, as in Example 1, then we can examine the maximal transfers as the relevant benchmark. The possibilities of avoiding war are still 
reduced relative to the commitment case, but the comparative statics are similar.

In particular, the unbiased peace result still holds for the case of a proportional $p$ function.

PROPOSITION 4 (Unbiased Peace without Commitment): If the probability of winning is proportional to relative wealth, then two unbiased countries $\left(B_{i}=B_{j}=1\right)$ will never go to war if they can make transfers to each other (even without commitment).

\section{PROOF:}

In the case of proportional winning probabilities, we know that an unbiased country will not wish to go to war with or without transfers.

This is clearly not true for all probability of winning functions. What is subtle is that, while it is true for proportional probabilities, it is not true for probability functions that are either less sensitive to relative changes in wealth or more sensitive to relative changes in wealth. This is seen as follows. First, consider a case where $p$ is constant and equal to $1 / 2$. In this case, a smaller country will wish to go to war with a larger one, as it has relatively little at risk and much to gain. The transfer that a larger country is willing to make is relative to its expected losses from a war. After having received a transfer, the small country could still have relatively more to gain from a war than it expects to lose. ${ }^{24}$ At the other extreme, where the country with higher wealth wins for sure, it is the larger country that is the aggressor. The smaller country is willing to pay something to avoid a war, but not its entire wealth. After having received a transfer, the larger country can still want to go to war, provided there is enough wealth left in the smaller country to justify the cost of war, as the larger country will win for sure. ${ }^{25}$

\footnotetext{
${ }^{24}$ For a numerical example, suppose that $w_{j}=1$ and $w_{i}=10$, and that $C=0.1$ and $G=0.2$. The maximal transfer that $i$ is willing to make is 1.9. If such transfers were made, the smaller country would have wealth 2.9 and the larger 8.1 . The smaller country would still wish to go to war.

${ }^{25}$ For a numerical example, suppose that $w_{i}=20$ and $w_{j}$ $=25$, and $C=0.1$ and $G=0.4$. Here the maximal transfer that $i$ is willing to make is 10 . After such a transfer, the wealths are $w_{i}=10$ and $w_{j}=35$. A war then costs the larger
}

\section{Endogenous Bias}

As political bias affects a country's decisions of whether to go to war and whether it receives or makes transfers, it is a critical dimension of a country. Most important, it could be that the representative citizen (that is, an unbiased citizen) of a country would prefer to have a biased leader. As such, we ask which political bias a country prefers its leader to have, as viewed from the perspective of a representative (unbiased) citizen. This is relevant not only because some countries choose their leaders, but also because it tells us which country leaders might best benefit its citizens.

We start by noting that in the absence of any transfers, the representative citizen of a country always prefers an unbiased leader over any other leader. In the absence of any transfers, the only decision is whether or not to go to war, and the representative (unbiased) citizen would prefer to have a decision maker who makes the same decisions the citizen would. An unbiased decision maker makes the same decisions that the representative citizen would, while someone with any bias would make different decisions in at least some contexts.

Now consider the case in which transfers are available and there is commitment. Here, having a biased leader can potentially benefit a country, as such a leader may extract transfers from other countries. ${ }^{26}$ It is useful to start with an example.

Example 5. Endogenous Bias and a Hawk-Dove Outcome: Let $w_{1}=w_{2}=100$ and $p(w, w)=1 / 2$. Let $C=0.1$ and $G=0.4$.

In the absence of transfers, a country would choose to attack the other if and only if its leader's bias is above 1.5. It is also useful to note that an unbiased leader is willing to pay up to 10 to avoid war.

So let us examine what happens for different combinations of biases of the leaders. To keep things simple, let us suppose that the bias levels that can be chosen are either 1 or 3 (which, as we

country 3.5 , but yields 4 in gains (as it wins for certain), and so the larger country will still go to war.

${ }^{26}$ This can be seen as an example of a delegation game, where players might like to have agents play for them who have different preferences from their own (e.g., see Fershtman and Judd 1987). See also Alastair Smith (1998). 
shall see shortly, correspond to extremes of the equilibria). If both countries have leaders with bias 3 , then war is unavoidable. If both countries have leaders with bias 1 , then no war occurs and no transfers are made. If one country has a leader with bias 1 and the other with bias 3 , then a transfer of exactly 10 occurs and the countries do not go to war.

In such a situation, we can think of "equilibrium" biases. Two countries choosing their leaders' biases in this example are essentially playing a Hawk-Dove game. The unique (pure-strategy) type of equilibrium is for one of the countries to have a biased leader and the other not to.

More generally, the presence of transfers provides incentives for countries to select leaders with high bias (more hawkish looking than the citizens would want in the absence of strategic considerations). The example above suggests, however, that this cannot generally be true for both countries, since the representative citizens prefer to avoid war. Hence, the model suggests a simple reason for the coexistence of endogenously biased and unbiased leaders in equilibrium.

We can state this more generally. The game is described as follows. Fix $w_{1}, w_{2}, C, G$, and $p$. Countries simultaneously choose $B_{1}, B_{2}$. If there are mutually acceptable transfers that would avoid war in a case where war would occur in the absence of transfers given $B_{1}, B_{2}$, then the minimum transfer to avoid war is made and there is commitment so that no war then ensues. ${ }^{27}$ If there are no mutually acceptable transfers that would avoid war, then war ensues. If neither country wishes to go to war, then no transfers are made and there is no war.

An equilibrium is a pair $B_{1}, B_{2}$ such that for each $i$ there does not exist any $B_{i}^{\prime}$ such that the expected utility of an unbiased citizen of country $i$ in the game is greater under $B_{i}^{\prime}, B_{j}$ than under $B_{i}, B_{j}$.

PROPOSITION 5: Consider the endogenous bias game in a situation where $1>p_{i}\left(w_{i}, w_{j}\right)$ $>0 .{ }^{28}$

\footnotetext{
${ }^{27}$ We could work with any predictable transfer scheme.

${ }^{28}$ In the extreme case where one of the countries wins for certain, the existence of a pure strategy equilibrium appears to be an issue unless we put an upper bound on the possible bias choices.
}

(i) There always exists an equilibrium that avoids war. In any such equilibrium $B_{1}$ $\geq 1$ and $B_{2} \geq 1$, with at least one holding strictly.

(ii) The set of equilibria that avoid war is the pairs $\left(B_{1}, B_{2}\right)$ such that $B_{1} \geq 1$ and $B_{2} \geq 1$ and either

$$
\begin{aligned}
\text { - } & B_{1} \geq \frac{C w_{1}}{G w_{2} p_{12}}+\frac{p_{21} w_{1}}{p_{12} w_{2}} \text { and } B_{1}\left(B_{2}-\frac{C w_{2}}{G w_{1} p_{21}}\right) \\
= & 1+\frac{C}{G p_{21}}
\end{aligned}
$$

or

$$
\begin{aligned}
& \text { - } B_{2} \geq \frac{C w_{2}}{G w_{1} p_{21}}+\frac{p_{12} w_{2}}{p_{21} w_{1}} \text { and } B_{2}\left(B_{1}-\frac{C w_{1}}{G w_{2} p_{12}}\right) \\
& =1+\frac{C}{G p_{12}} .
\end{aligned}
$$

(iii) There exist equilibria where there is war if and only if $p_{12} w_{2}>C w_{1}$ and $p_{21} w_{1}>C w_{2}$.

\section{PROOF:}

See the Appendix.

The pure strategy "war" equilibria in (iii) are somewhat less reasonable than the other equilibria in the following sense. In such "war" equilibria, a country chooses a very high bias simply because it expects the other country to choose such a high bias that there is no chance of finding transfers that will avoid a war in the second stage. These strategies are not quite eliminated via an elimination of dominated strategies, as it is still conceivable that the other country will choose a low bias (below 1) and then the country will get a large payment, and so an iterative elimination of weakly dominated strategies is needed to rule out such behavior. ${ }^{29}$ Alternatively, if one country moves first, there is a unique subgame perfect equilibrium outcome: it is the first country's most preferred of the equilibrium outcomes described in Proposition 5, as effectively that country becomes a Stackleberg leader picking its highest possible bias where war is avoided.

The result above gives us an idea that there is a well-defined sense in which countries would prefer to have biased leaders. The argument then

\footnotetext{
${ }^{29}$ A representative citizen can generally lose only by having a leader with a bias lower than 1 compared to having a leader with a bias of 1 (as the only time that changes outcomes is where the leader would make transfers that are larger than the citizen would be willing to make to avoid war).
} 
suggests that we should end up seeing an outcome where at least one of the countries has a high bias and both biases are at least 1 , and we should expect to see war avoided.

If we enrich this analysis by introducing some natural sort of uncertainty at the time where the bias is chosen, so that countries might not have a perfect prediction of their future wealth or of the future technology of war, then we should see positive biases and occasional wars. In particular, if we then examine an equilibrium with uncertainty, countries may end up choosing biases strictly above 1 and going to war with some positive probability. Announcing a bias below 1 is dominated by choosing a bias of 1 , and a situation in which both countries choose a bias of 1 is not an equilibrium, as one country would gain by raising their announcement. So, equilibrium will involve some higher announcements, but now the countries also trade off some probability of potential wars, depending on how the later uncertainty about relative wealth and probabilities of winning a war works out. Exactly how high that bias would be and how frequently war would ensue depend on the specifics of the uncertainty. The availability of transfers and enforceable treaties may therefore be themselves indirect causes of war, insofar as they give ex ante incentives to (s)elect biased leaders, and to the degree that there is substantial uncertainty about the circumstances that the leaders will face.

As the trade-offs and basic ideas are fairly clear, and solving for the general form of equilibrium appears to be intractable, we illustrate these ideas with a simple extension of Example 5.

Example 6. Endogenous Bias with Uncertainty: Let $w_{1}=w_{2}=100, C=0.1$, and $p_{12}(100,100)$ $=1 / 2$. The uncertainty is about the potential gains from war. It is $G=0.4$ with probability $\pi$ and $G=0.6$ with probability $1-\pi$.

We examine a case where country 1 chooses its bias first, and this is observed before country 2 chooses its bias.

If $\pi=1$, then country 1 chooses a bias of 3 and country 2 chooses a bias of no more than 1 , country 2 makes a transfer of 10 to country $1,{ }^{30}$

\footnotetext{
${ }^{30}$ With the protocol of using the minimum transfer necessary, the transfer needed to keep 1 from choosing war is
}

and war is avoided. If $\pi=0$, then the equilibrium is for country 1 to choose a bias of 2 and country 2 to choose a bias of no more than 1 ; country 2 makes a transfer of 10 to country 1 and again war is avoided.

With uncertainty, all equilibria have the following play on the equilibrium path: for higher values of $\pi$, country 1 will choose a bias of 3 and country 2 will choose a bias of no more than 1 , and with probability $\pi$, a war will be avoided, but with a probability of $(1-\pi)$ a war will ensue. Once $\pi$ is low enough, country 1 plays a "safer" strategy of choosing a bias of 2 and country 2 responds with a bias of no more than 1 and war is always avoided. In this case, with probability $1-\pi$ country 1 gets a transfer of 10 , but with probability $\pi$ the country ends up getting a lower transfer of 5. It is straightforward to verify the statements above, so we simply outline the main arguments. First, note that in any equilibrium, country, 1 will choose a bias of either 2 or 3 . Choosing a bias above 3 is worse than choosing a bias slightly below 3 , as the first strategy always leads to war while the second one leads to a response that leads to transfers in some cases and to an improvement for country 1 . Choosing a bias below 3 and not equal to 2 is worse for country 1 than slightly increasing the bias, as this sometimes leads to a higher transfer (and it can be checked that country 2's response will result in war under the same circumstances and in higher transfers when transfers are made). Thus, things boil down to a choice of either 2 or 3 for country 1 . It is then easy to check that a bias of 2 will be chosen by country 1 only when it would be met with a response of a bias of no more than 1 by country 2 , and otherwise a bias of 3 will be chosen and this must be responded to with a bias of no more than 1 in equilibrium (or else a deviation to a slightly lower bias would be improving, and we have already argued that such a bias is not part of an equilibrium).

\section{Stability and Alliances}

Let us now consider settings where there are many countries.

the same for any bias that country 2 chooses, provided that bias does not exceed 1 . 


\section{A. Bilateral Stability}

Consider some set of countries $\{1, \ldots, n\}$, their respective wealths $\left(w_{1}, \ldots, w_{n}\right)$ and biases $\left(B_{1}, \ldots, B_{n}\right)$, a technology of war that is specified for each pair $i j, p_{i j}$, and relative costs and gains $C$ and $G$. We say that such a configuration of countries is bilaterally stable if there would be no war between any two of the countries if they met, even in the absence of any transfers. ${ }^{31}$

Bilateral stability is characterized by having (3) fail to hold for each pair of countries. We can see directly from (3) that if the relative costs of war $(C / G)$ are high enough, then we will have bilateral stability. Beyond that, we need to know more about the probability of winning function and how that compares to the biases. The following proposition outlines one case where bilateral stability holds.

PROPOSITION 6 (Democratic Stability): If all countries are politically unbiased and the probability of winning a war is proportional to wealth, then the countries are bilaterally stable.

\section{PROOF:}

This follows directly from Remark 1 .

We can also say something about how biased countries can be while still having bilateral stability. The following proposition works for more general war technologies, but starting from a point where all countries have equal wealth.

PROPOSITION 7: If all countries have equal wealth and $p_{i j}$ is symmetric, ${ }^{32}$ then the configuration is bilaterally stable if and only if $B_{j} \leq$ $1+2 \frac{C}{G}$ for all $j$.

\section{PROOF:}

This follows from (3), setting $p_{j i}=1 / 2$ and $w_{i}$ $=w_{j}$.

\footnotetext{
${ }^{31}$ In international relations there are a variety of notions of stability. Given that in a bilaterally stable situation no resource is transferred by definition, this notion is closest to that of "resource stability" in Emerson M.S. Niou et al. (1989).

$$
{ }^{32} p_{i j} \text { is symmetric if } p_{i j}\left(w, w^{\prime}\right)=p_{j i}\left(w^{\prime}, w\right) .
$$
}

Beyond these propositions, bilateral stability can be directly characterized by bilateral checks of (3).

\section{B. Coalitional Stability}

Another question we address when examining many countries concerns alliances and coalitional stability.

One way of modeling alliances is as follows. When a set $K$ of countries form an alliance, the decision maker from country $i$ still has $a_{i} w_{i}$ in terms of wealth at risk (and thus loses $(C+G) a_{i} w_{i}$ if a war is lost), and shares $a_{i}^{\prime} w_{i} / \sum_{j \in K} w_{j}$ of the spoils of war or transfers. Alliance decisions are unanimous (pure collective action). Each country's decision maker must be willing to undertake an offensive war in order for it to happen. The default is not to attack unless the coalition is unanimous about doing so, which reflects the idea that the coalition might dissolve otherwise..$^{33}$ The maximum total transfer that an alliance might make in order to avoid a war is the maximum sum of transfers across its members, such that each would be willing to contribute their part in order to avoid a war.

The technology of war is presumed to be given by a function $p$ which depends only on the total wealth of the warring alliances.

With this structure of alliances in mind, we can consider whether there exist configurations of alliances such that the alliances are bilaterally stable (no alliance wishes to attack any other alliance); and whether there exist configurations of alliances that are immune to deviations by any subset of countries (which might quit their current alliance and join with others to form a new alliance). We can also consider

\footnotetext{
${ }^{33}$ As explained in Giovanni Maggi and Morelli (2006), a unanimity requirement for collective action is the norm when the participation of all allies is necessary and the value of future expected cooperation with the other allies is not sufficient to convince a dissenting member to go along with the decision of a majority. When the participation of all allies is not necessary, the formation of a "coalition of the willing" can suffice. We do not consider this distinction here. See James D. Morrow (1991) for the view that alliances entail a pledge of future coordination between the allies. Note also that the degree of consensus necessary in an alliance could be different depending on whether it is a defensive or an offensive alliance. A world with large defensive alliances and small offensive ones could be quite stable.
} 
weaker deviations, asking whether there is any single country that wishes to quit its current alliance and would be unanimously accepted into some other alliance. Finally, we can differentiate between offensive and defensive alliances.

Let us begin with a couple of examples that make clear some of the issues that arise. The first example illustrates why there are interesting alliance issues that arise and why we might want to move beyond simply studying bilateral stability.

Example 7. Consider three equal sized countries with $w_{1}=w_{2}=w_{3}$ and $B_{1}=B_{2}=B_{3}$. If the corresponding $B_{1}$ 's are not too high, this could be bilaterally stable. However, this is not necessarily coalitionally stable. Two countries might have an incentive to form an (offensive) alliance and exclude the third country. This could strengthen them so that they might either wish to go to war regardless of any transfers, and both benefit in expected terms from doing so, or to obtain a transfer. For example, in the case of unbiased countries and higher wealth winning, two countries that band together expect to gain from going to war with the third country.

The next example illustrates that countries could form alliances, not for offensive purposes (as above), but instead for defensive purposes.

Example 8. Consider three countries where one's wealth is twice the size of each of the others. By forming an alliance, for some choices of $B_{i}$ 's, the two smaller countries avoid being attacked or having to pay a transfer. For example, if it is the greatest wealth that wins, then separately the two smaller countries are sure to lose a war, while if allied they have an even chance of winning.

Clearly, from the examples above, it is possible that there will not exist any configuration of countries or alliances that is bilaterally stable (so that no alliance would attack another in the absence of any transfers).

These examples also suggest that the incentive to form an alliance (offensive and defensive, respectively) derives from the sensitivity of the $p$ function. If $p$ were independent of wealth, then countries would not gain at all from forming an alliance. If the probability of winning were proportional to the relative wealth for any pair of potential opponents (countries or alliances), then if countries were not too biased, the core would be very large, as unbiased countries or alliances would not wish to go to war in the face of such a technology. Thus, the incentives to form alliances are more prevalent when relative wealth swings the anticipated outcome more dramatically.

When we allow for configurations with heterogeneity of bias levels, it is difficult to characterize conditions for the nonemptiness of the core, or to determine which alliances are most likely to form. However, we can still explore a few things.

It is possible to have alliance configurations that are bilaterally stable and such that no individual country would strictly want to quit its existing alliance either to be alone or to join another alliance. Let us call such an alliance configuration individually stable. Let $w$ denote the total wealth of an alliance.

PROPOSITION 8: Consider any parameters $C$ and $G$, and any continuous $p$ such that $p(w, W)$, $w / W$ when $w / W$ approaches $0 .{ }^{34}$ If there exist at least two countries with biases close enough to 1 , biases of countries are bounded above, and there are enough countries such that each country's wealth is sufficiently small relative to the total world wealth, then there exists a division of countries into two alliances that is individually stable. In such a situation, a single alliance of all countries is also individually stable.

The proof is relatively straightforward, and hence we simply outline it. Separate the two countries with lowest biases. Then, around each, form an alliance so that the total wealths in the two alliances are as close to each other as possible. Given the continuity of $p$, the probability of either alliance winning a war approaches $1 / 2$. With a small enough bias, the least biased country in each alliance will prefer not to go to war. Consider any country switching alliances. Their wealth, if small enough relative to total wealth, will make too small a change in probabilities of outcomes to change the incentives

\footnotetext{
${ }^{34}$ More precisely, consider $p$ such that $p(w, W) W / w \rightarrow 0$ as $w \rightarrow 0$, for any fixed $W>0$.
} 
of the alliances. ${ }^{35}$ The only remaining possibility is that a country could gain from autarchy. However, in that case, providing countries are small enough relative to total wealth, even with maximal bias, (3) fails to hold for the departing country, as its probability of winning is so small relative to the maximal potential gains that it will not have an incentive to go to war with one of the (large) alliances.

Comparing the situation described in example 7 with the constructed stability of a pair of alliances in Proposition 8, one can conclude that in our model a "bipolar" system will (under the right circumstances) be stable when a multipolar one may not be. ${ }^{36}$

\section{Further Results and Discussion}

As should be clear from some of the analysis above, this basic model of political bias opens the door for much future research. Let us comment on a few of the more obvious areas for further exploration.

First of all, one can examine the predictions of the model empirically. One can do this by a structural fit of the model, estimating wealth, costs, gains, and war technology $(p)$ directly from the data, and either imputing the biases or estimating them based on other political variables. The predictions of the model about the role of the technology of war could also lead to interesting empirical research on historical data.

One can also develop variations on the model that endogenize various parameters (other than bias) that we have taken to be exogenous. Let us mention a few ideas in this direction.

- The model could be coupled with a growth model so that wealths change over time. As wealths change, so will incentives to go to war (and incentives to capture territory to help with growth), and one could track how

\footnotetext{
${ }^{35}$ The only possible exception is if the least biased country leaves and the remaining countries are strongly biased, but then that can lead only to the biased country alliance wanting to attack the other alliance, which does not benefit the country that switched.

${ }^{36}$ This is in line with the general concerns about tripolar systems, for instance, as expressed by Morton A. Kaplan (1957). For counterarguments about the special stability features of tripolar systems, see Charles W. Ostrom, Jr., and John H. Aldrich (1978) and Wagner (1986).
}

the economics of growth interacts with the incentives for international conflict.

- One could enrich the technology of war to allow for investments in arms, so that the probability of winning a war depended on military spending and not simply on wealth directly.

- We could enrich the model to endogenize the timing and choice of confrontation, so that we not only examine stability or the choices of two countries once faced with war, but also model more completely how it is that two countries start to consider a war and how this might depend on the more general environment.

Beyond such enrichment of the model, we note other aspects of the current model that deserve further attention. We have limited the transfers that can be made to those from one country to another. For example, we have not considered situations where transfers can be made in both directions simultaneously, nor have we allowed a country to buy off another country's leader directly, or a country to buy off its own leader. To see some of the issues, note that under a strict interpretation of the model, biased leaders would like to make transfers back and forth to each other. They see only part of the costs and appropriate a larger share of the gains of any mutual transfers. Essentially, they could loot each other's countries. While this is plausible within the model, it is partly because we have modeled all sorts of distorted incentives that leaders might have to go to war (glory, power gains, personal ambitions, etc.) through the lens of a pure financial bias. Nevertheless, while such cross-looting activity might seem contrived, it is worthy of further study, as the incentives for such activity are strong. This is also true simply of allowing a country to make transfers directly to the leader of a country, as this can make the impact of a transfer larger. Neither of these completely eliminates war, even with commitment, as the biases of the two countries' leaders may be too high to overcome; but this could add leverage to the transfers. Of course, if all parties involved can make transfers, and complete commitment on the part of all parties is possible, then an efficient outcome can be realized. So some imperfection in the bargaining is needed for wars to occur. 


\section{A. Dynamics}

As our analysis has been static, and yet international relations are clearly dynamic, we close with some observations on this topic.

The most basic and important aspect that dynamics introduces is that as countries get richer, their incentives change. As a country $j$ has won past wars, three things happen. First, its wealth increases, and so the $w_{i j}=w_{i} / w_{j}$ ratios it faces will decrease. This in turn has a second effect which is that $p_{j i}$ increases. Third, as more wealth is acquired, the pivotal agent's percentage share of the wealth increases and so $B_{j}$ decreases. To see this, note that before a war the agent's share is $a_{j}$. After the war, if the country wins, the agent's share is

$$
\frac{a_{j}(1-C) w_{j}+a_{j}^{\prime} G w_{i}}{(1-C) w_{j}+G w_{i}} .
$$

If $a_{j}^{\prime}>a_{j}$, then this new share is larger than $a_{j}$. Thus, the new $B_{j}$ is $a_{j}^{\prime}$ over this new share, and so as a country keeps winning wars, $B_{j}$ will decrease.

Let us examine the implications of these changes over time. We know from (3) that a country will want to go to war (without consideration of transfers) if

$$
p_{j i}>\frac{1+\frac{C}{G}}{1+B \frac{w_{i}}{w_{j}}} .
$$

$$
1-p_{j i}>\frac{1+\frac{C}{G}}{1+B_{i} w_{j i}} \text {. }
$$

Part (iii) follows directly from (3) and (10), as both right-hand sides are increasing in $C / G$.

Next, note that from (3) and (10) it follows that both countries want to go to war if and only if

$$
1-\frac{1+\frac{C}{G}}{1+B_{i} w_{j i}}>p_{j i}>\frac{1+\frac{C}{G}}{1+B_{j} w_{i j}} .
$$

side will also go up as $p_{j i}$ increases. While we cannot say what the short-term effects of this are, we can say that a country will not wish to keep going to war for too long. This follows from noting that $p_{j i}$ is bounded above by 1 , while $w_{i j}$ can go to 0 . As a country becomes much wealthier than other countries, it no longer desires to go to war, as the right-hand side of (9) will converge to $1+(C / G)$, while the left-hand

side is bounded above by 1 . Essentially, even if the country is sure to win the war, it does not go to war because the costs outweigh the Thus, the model displays a novel "endogenous limit to the expansion of an empire," in contrast with the systemic explanations in the literature.

Interestingly, depending on the technology little to lose. ${ }^{38}$ Whether or not this is the case faced the temptation of war or gone to war sufficiently many times), a war between countries per very different wealth (winners and losers of past wars, respectively) will be possible only if

\section{APPENDIX}

$$
\text { Let } w_{j i}=w_{j} / w_{i} \text {. }
$$

We know that (3) is the condition to satisfy for $j$ to be willing to go to war against $i$ in the absence of transfers. Similarly, country $i$ wishes to go to war with country $j$ if and only if

As we see from this, if a country has become the right-hand side of this expression will have increased as both $B_{j}$ and $w_{i j}$ will have decreased (if we are holding the wealth of a given opponent constant). On the other hand, the left-hand

\footnotetext{
${ }^{37}$ It might be more reasonable to presume that the costs of going to war against a much smaller country are small. If, however, the costs of going to war have any lower bound, the conclusion will still hold.

${ }^{38}$ Again, this seems to be consistent with the history of how the largest empires came to an end after a sequence of attacks by weaker challengers.
} 
It is clear that if $B_{i}=B_{j}=1$, then the inequalities in (11) require that

$$
1-\frac{1+\frac{C}{G}}{1+w_{j i}}>\frac{1+\frac{C}{G}}{1+w_{i j}} .
$$

To see that this is impossible, rewrite the inequality above as

$$
1+w_{i j}-\frac{1+\frac{C}{G}}{w_{j i}}>1+\frac{C}{G} .
$$

This simplifies to

$$
-w_{i j} \frac{C}{G}>\frac{C}{G},
$$

which is clearly impossible. This proves (i).

The proof of (ii) derives from the following observation: the left-hand side of (11) converges to 1 as $B_{i}$ gets large, and the right-hand side of (11) converges to 0 as $B_{j}$ gets large.

\section{PROOF OF PROPOSITION 2:}

As $j$ wishes to go to war but $i$ does not, (3) holds but (10) does not. The condition that needs to be satisfied for country $j$ to no longer wish to go to war against $i$ if offered $t_{i j}>0$ is

$$
\begin{aligned}
& (1-C-G) a_{j} w_{j}+p_{j i} G\left(a_{j} w_{j}+a_{j}^{\prime} w_{i}\right) \\
& \quad \leq a_{j} w_{j}+a_{j}^{\prime} t_{i j} .
\end{aligned}
$$

This simplifies to

$$
p_{j i} G\left(w_{j}+B_{j} w_{i}\right) \leq(C+G) w_{j}+B_{j} t_{i j}
$$

Similarly, the condition for $i$ to be willing to make a transfer $t_{i j}>0$ to avoid a war is

$$
\begin{aligned}
& \left(1-p_{j i}\right) G\left(w_{i}+B_{i} w_{j}\right) \\
& \quad \leq(C+G) w_{i}-t_{i j} .
\end{aligned}
$$

Note that we assume that the pivotal agent in country $j$ gets the same proportion $\left(a_{j}^{\prime}\right)$ of $t_{i j}$ as it would if it were a spoil of war, and the pivotal agent in country $i$ pays the same proportion $\left(a_{i}\right)$ of $t_{i j}$ as it risks its wealth in a war.

Let $t_{i}^{p}\left(B_{i}\right)$ be the transfer that makes country $i$ (which wishes to avoid war) indifferent between going to war and paying such a transfer, i.e., the transfer that makes (13) hold as equality. In other words, $t_{i}^{p}\left(B_{i}\right)$ is the maximum transfer that $i$ is willing to make in order to avoid the war. Then, from (13),

$$
t_{i}^{p}\left(B_{i}\right)=(C+G) w_{i}-\left(1-p_{j i}\right) G\left(w_{i}+B_{i} w_{j}\right) .
$$

Substituting (14) in (12), a transfer can be made so that country $j$ no longer wishes to go to war if

$$
\begin{aligned}
p_{j i} G\left(w_{j}+B_{j} w_{i}\right) \leq & (C+G) w_{j}+B_{j}(C+G) w_{i} \\
& -B_{j}\left(1-p_{j i}\right) G\left(w_{i}+B_{i} w_{j}\right) .
\end{aligned}
$$

This can be rewritten as

$$
\frac{C}{G} \geq \frac{\left(1-p_{j i}\right)\left(B_{i} B_{j}-1\right)}{1+B_{j} w_{i j}} .
$$

When we combine this with (3) we obtain the following characterization of when transfers avoid a war:

$$
\begin{aligned}
p_{j i}\left(1+B_{j} w_{i j}\right)-1>\frac{C}{G} \\
>\frac{\left(1-p_{j i}\right)\left(B_{i} B_{j}-1\right)}{\left(1+B_{j} w_{i j}\right)} .
\end{aligned}
$$

The comparative statics in the proposition are then clear.

\section{PROOF OF PROPOSITION 3:}

Given proposition 1(i), we know that when two unbiased countries meet, the situation without transfers is either such that they both wish to avoid war or that one country alone wishes to go to war. If the situation is the former, we are done. If it is the latter, then assume without loss of generality that $j$ is the one that wants to go to war and $i$ is the one that does not. We have established above that, in this case, the availability of transfers eliminates the incentive of $j$ to go to war if (15) holds. Thus, the result follows, noting that the right-hand side of (15) is 0 with two unbiased countries.

\section{PROOF OF PROPOSITION 5:}

Recall from (14) that $t_{i}^{p}\left(B_{i}\right)$ is the maximum transfer that $i$ would be willing to make to avoid war in a case where $i$ would not (strictly) desire 
to go to war in the absence of any transfers, and that

$$
t_{i}^{p}\left(B_{i}\right)=G w_{i} p_{j i}+C w_{i}-p_{i j} G B_{i} w_{j} .
$$

Let $t_{j}^{r}\left(B_{j}\right)$ be the minimum transfer that $j$ would be willing to accept to avoid war in a case where $j$ would strictly desire to go to war in the absence of any transfers. Thus, from (12) it follows that

$$
t_{j}^{r}\left(B_{j}\right)=G w_{i} p_{j i}-\frac{1}{B_{j}}\left(C w_{j}+G w_{j} p_{i j}\right)
$$

Let $B_{i}^{w}>0$ denote the level of bias such that $i$ is just indifferent between war and not going to war. The existence of such a level is guaranteed by the assumption that $1>p_{i j}>0$.

Note that $t_{i}^{p}\left(B_{i}\right)>0$ if and only if $B_{i}<B_{i}^{w}$ (i.e., when $i$ strictly prefers to avoid war), and thus equality holds in both at the same time. Also, note that $t_{j}^{r}\left(B_{j}\right)>0$ if and only if $B_{j}>B_{j}^{w}$ (i.e., when $j$ strictly prefers to go to war), and thus equality holds in both at the same time.

Let us now prove (i). First, consider the case where $C w_{i}-p_{i j} G w_{j} \geq 0$ for some country $i$. This implies that $t_{i}^{p}(1)>t_{j}^{r}\left(B_{j}\right)$ for each $B_{j}$. So, pick any $B_{j}>B_{j}^{w}$. Then, pick $B_{i}$ such that $t_{i}^{p}\left(B_{i}\right)$ $=t_{j}^{r}\left(B_{j}\right)$. Such a $B_{i}$ exists and is less than $B_{i}^{w}$ since $t_{i}^{p}(1)>t_{j}^{r}\left(B_{j}\right)>0$ and $t_{i}^{p}\left(B_{i}^{w}\right)=0$, and $t_{i}^{p}(\cdot)$ is decreasing in $B_{i}$. It follows easily that this pair is an equilibrium.

Next, consider the case where $C w_{i}-p_{i j} G w_{j}$ $<0$ for each $i$. Without loss of generality, let $i$ be a country that does not want to go to war when unbiased (noting from the unbiased peace result that at least one country does not wish to go to war at a bias of 1). In this case, it follows that $t_{i}^{p}(1)<G w_{i} p_{j i}$. Find $B_{j}>B_{j}^{w}$ such that $t_{j}^{r}\left(B_{j}\right)=$ $t_{i}^{p}\left(B_{i}\right)$. We know that such a $B_{j}$ exists since $t_{j}^{r}\left(B_{j}\right)$ $\rightarrow G w_{i} p_{j i}$ as $B_{j} \rightarrow \infty$, and since $t_{j}^{r}\left(B_{j}^{w}\right)=0$ and $t_{j}^{r}(\cdot)$ is increasing. Again, it follows easily that this pair is an equilibrium.

Finally, we need to show that in any equilibrium where war is avoided, $B_{i} \geq 1, B_{j} \geq 1$, and at least one is greater than 1 . Let $B_{i}, B_{j}$ be an equilibrium where war is avoided. It must be, wlog in labeling, that $B_{i} \leq B_{i}^{w}$ and $B_{j} \geq B_{j}^{w}$, and $t_{j}^{r}\left(B_{j}\right) \leq$ $t_{i}^{p}\left(B_{i}\right) \cdot{ }^{39}$ It must then also be that $t_{j}^{r}\left(B_{j}\right)=t_{i}^{p}\left(B_{i}\right)$,

\footnotetext{
${ }^{39}$ If both were strictly more than their respective indifference levels, then there would be no transfers to avoid
}

as otherwise $j$ could deviate by raising their bias and be strictly better off. It follows that $B_{i} \geq 1$, or else $i$ would be better off deviating and stating 1 (and then going to war, since $t_{i}^{p}\left(B_{i}\right)>t_{i}^{p}(1)$ when $\left.B_{i}<1\right)$. Similarly for $j$. If both were equal to 1 , then it would be direct to check that $t_{i}^{p}(1)>$ $t_{j}^{r}(1)$, which is then a contradiction.

Next, let us show (ii). We know from above that $B_{i} \geq 1$ and $B_{j} \geq 1$. The other conditions, respectively, are precisely that one country (say $j$ ) weakly wishes to go to war, and that $t_{j}^{r}\left(B_{j}\right)$ $=t_{i}^{p}\left(B_{i}\right)$. Following the logic above, these are necessary for equilibrium, and are also clearly sufficient.

Finally, we show (iii). If $p_{i j} w_{j} \leq C w_{i}$, then it follows that $t_{i}^{p}(1)>t_{j}^{r}\left(B_{j}\right)$ for all $B_{j}$. This implies that regardless of $j$ 's announcement, $i$ could avoid a war and make a payment of less than $t_{i}^{p}(1)$ by setting $B_{i}=1$. Since $i$ prefers this to war, war could not be an equilibrium outcome. Thus, any war equilibrium requires that $p_{i j} w_{j}>$ $C w_{i}$ for both countries. To see the converse, note that if $p_{i j} w_{j}>C w_{i}$ for both countries, then there exists $B_{j}>B_{j}^{w}$ such that $t_{i}^{p}(1)<t_{j}^{r}\left(B_{j}\right)$ and similarly there is such a $B_{i}>B_{i}^{w}$ with $t_{j}^{p}(1)<t_{i}^{r}\left(B_{i}\right)$. Such a pair form an equilibrium where war ensues, since both strictly prefer to go to war, and they could avoid war only by announcing some bias below 1 and making a payment above their maximum willingness to pay (as they are truly unbiased).

\section{REFERENCES}

-Baliga, Sandeep, and Tomas Sjöström. 2004. "Arms Races and Negotiations." Review of Economic Studies, 71(2): 351-69.

Blainey, Geoffrey. 1973. The Causes of War. New York: The Free Press.

Bueno de Mesquita, Bruce. 1981. The War Trap. New Haven: Yale University Press.

Bueno de Mesquita, Bruce, and Randolph M. Siverson. 1995. "War and the Survival of Political Leaders: A Comparative Study of Regime Types and Political Accountability."

war. If both were strictly less, then $j$ could deviate and set $B_{j}$ to a level above $B_{j}^{w}$ so that $0<t_{j}^{r}\left(B_{j}\right) \leq t_{i}^{p}\left(B_{i}\right)$ and strictly gain. It must be that the transfers are compatible, or else war would not be avoided. 
American Political Science Review, 89(4): 841-55.

Bueno de Mesquita, Bruce, James D. Morrow, Randolph M. Siverson, and Alastair Smith. 1999. "An Institutional Explanation of the Democratic Peace." American Political Science Review, 93(4): 791-807.

Bueno de Mesquita, Bruce, James D. Morrow, Randolph M. Siverson, and Alastair Smith. 2003. Logic of Political Survival. Cambridge, MA: MIT Press.

Chiozza, Giacomo, and Hein E. Goemans. 2004. "International Conflict and the Tenure of Leaders: Is War Still Ex Post Costly?" American Journal of Political Science, 48(3): 604-19.

Clausewitz, Carl von. 1832. On War. Trans. and ed. by Michael Howard and Peter Paret. Princeton: Princeton University Press, 1976.

- Crawford, Vincent P. 1982. "A Theory of Disagreement in Bargaining." Econometrica, 50(3): 607-37.

Downs, George W., and David M. Rocke. 1994. "Conflict, Agency, and Gambling for Resurrection: The Principal-Agent Problem Goes to War." American Journal of Political Science, 38(2): 362-80.

Doyle, Michael W. 1986. "Liberalism and World Politics." American Political Science Review, 80(4): 1151-69.

-Fearon, James. 1995. "Rationalist Explanations for War." International Organization, 49(3): 379-414.

Fearon, James. 1996. "Bargaining over Objects that Influence Future Bargaining Power." Unpublished.

Fearon, James. 1997. "Signaling Foreign Policy Interests: Tying Hands versus Sinking Costs." Journal of Conflict Resolution, 41(1): 68-90.

Fershtman, Chaim, and Kenneth L. Judd. 1987. "Equilibrium Incentives in Oligopoly." American Economic Review, 77(5): 927-40.

Findlay, Ronald. 1996. "Towards a Model of Territorial Expansion and the Limits of Empires. "In The Political Economy of Conflict and Appropriation, ed. Michelle Garfinkel and Stergios Skaperdas, 41-56. New York: Cambridge University Press.

Gartzke, Erik A. 1999. "War Is in the Error Term." International Organization, 53(3): 567-87.

Harris, William V. 1979. War and Imperialism in Republican Rome 327-70 BC. Oxford: Oxford University Press.
Harrison, Mark. 2005. "Why the Rich Won: Economic Mobilization and Economic Development in Two World Wars." Unpublished.

-Hirshleifer, Jack. 1989. "Conflict and Rent-seeking Success Functions: Ratio vs. Difference Models of Relative Success." Public Choice, 63: 101-12.

Jervis, Robert. 1976. Perception and Misperception in International Politics. Princeton: Princeton University Press.

Jervis, Robert. 1978. "Cooperation under the Security Dilemma." World Politics, 30(2): 167-214.

-Jones, Stephen R. G. 1989. "Have Your Lawyer Call My Lawyer: Bilateral Delegation in Bargaining Situations." Journal of Economic Behavior and Organization, 11(2): 159-74.

-Jordan, James S. 2006. "Pillage and Property." Journal of Economic Theory, 131(1): 26-44.

Kaiser, David. 1990. Politics and War: European Conflict from Philip II to Hitler. Cambridge, MA: Harvard University Press.

Kant, Immanuel. 1795. “Toward Perpetual Peace: A Philosophical Sketch.” In Kant's Political Writings, ed. Reiss, 93-130. New York: Cambridge University Press, 1991.

Kaplan, Morton A. 1957. System and Process in International Relations, New York: Wiley.

Kirshner, Jonathan. 2000. "Rationalist Explanations for War?" Security Studies, 10(1): 143-50.

Lake, David A. 1992. "Powerful Pacifists: Democratic States and War." American Political Science Review, 86(1): 24-37.

Liberman, Peter. 1993. "The Spoils of Conquest." International Security, 18(2): 125-53.

-Maggi, Giovanni, and Massimo Morelli. 2006. "Self-Enforcing Voting in International Organizations." American Economic Review, 96(4): 1137-58.

Morgan, T. Clifton, and Sally H. Campbell. 1991. "Domestic Structure, Decisional Constraints, and War: So Why Kant Democracies Fight?" Journal of Conflict Resolution 35(June): 941-72.

Morrow, James D. 1991. "Alliances and Asymmetry: an Alternative to the Capability Aggregation Model of Alliances," American Journal of Political Science, 35(4): 904-33.

-Nash, John F. 1953. "Two-Person Cooperative Games," Econometrica, 21: 128-40.

Niou, Emerson M.S., Peter C. Ordeshook, and Gregory F. Rose. 1989. The Balance of Power: 
Stability in International Systems. New York: Cambridge University Press.

Ostrom, Charles W., Jr., and John H. Aldrich. 1978. "The Relationship Between Size and Stability in the Major Power International System." American Journal of Political Science, 22(4): 743-71.

Piccione, Michele, and Ariel Rubinstein. 2004. "Equilibrium in the Jungle." Unpublished.

Russett, Bruce. 1993. Grasping the Democratic Peace: Principles for a Post-Cold War World. Princeton: Princeton University Press.

Schelling, Thomas C. 1963. The Strategy of Conflict. New York: Oxford University Press.

Schelling, Thomas C. 1966. Arms and Influence. New Haven: Yale University Press.

Schwarz, Michael A., and Konstantin Sonin. 2004. "A Theory of Brinkmanship, Conflicts, and Commitments." Unpublished.

Smith, Alastair. 1998. "Fighting Battles, Winning Wars." Journal of Conflict Resolution, 42(3): 301-20.

Tarar, Ahmer. 2006. "Diversionary Incentives and the Bargaining Approach to War." International Studies Quarterly, 50(1): 169-188.

Tilly, Charles. 1992. Coercion, Capital, and European States: AD 990-1992. Oxford: Blackwell Publishers.

Wagner, R. Harrison. 1986. "The Theory of Games and the Balance of Power." World Politics, 38(4): 546-76.

Wagner, R. Harrison. 2000. "Bargaining and War." American Journal of Political Science. 44(3): 469-84.

Waltz, Kenneth. 1959. Man, the State, and War. New York: Columbia University Press. 


\section{This article has been cited by:}

1. Philip T. Hoffman. 2017. Public Economics and History: A Review of Fiscal Regimes and the Political Economy of Premodern States, Edited by Andrew Monson and Walter Scheidel. Journal of Economic Literature 55:4, 1556-1569. [Abstract] [View PDF article] [PDF with links]

2. Marco Nilsson. 2017. Causal beliefs and war termination. Journal of Peace Research 90, 002234331773012. [Crossref]

3. Eyal Pecht, Asher Tishler. 2017. Budget allocation, national security, military intelligence, and human capital: a dynamic model. Defence and Peace Economics 28:3, 367-399. [Crossref]

4. Nobuhiro Mizuno, Ryosuke Okazawa. 2017. Within-group heterogeneity and civil war. Economics of Governance 18:2, 153-177. [Crossref]

5. Paola Conconi, Nicolas Sahuguet, Maurizio Zanardi. 2017. Electoral incentives, term limits, and the sustainability of peace. European Journal of Political Economy . [Crossref]

6. Colin Krainin, John Slinkman. 2017. Bargaining with a biased autocrat. Journal of Theoretical Politics 29:2, 273-298. [Crossref]

7. Christoph Mikulaschek, Jacob N. Shapiro. 2017. Lessons on Political Violence from America's Post9/11 Wars. Journal of Conflict Resolution 002200271666980. [Crossref]

8. J. Tyson Chatagnier, Kerim Can Kavaklı. 2017. From Economic Competition to Military Combat. Journal of Conflict Resolution 13, 002200271561356. [Crossref]

9. Antonis Adam, Petros G. Sekeris. 2017. Self-Containment. Journal of Conflict Resolution 61:1, 173-203. [Crossref]

10. Kristy Buzard, Benjamin A.T. Graham, Ben Horne. 2016. Unrecognized States: A Theory of Self-Determination and Foreign Influence. Journal of Law, Economics, and Organization eww017. [Crossref]

11. Kai A. Konrad, Florian Morath. 2016. Evolutionary determinants of war. Defence and Peace Economics 27:4, 520-534. [Crossref]

12. Brian Crisher, Mark Souva. 2016. Domestic Political Problems and the Uneven Contenders Paradox. Foreign Policy Analysis orw001. [Crossref]

13. Thomas M. Dolan. 2016. Go Big or Go Home? Positive Emotions and Responses to Wartime Success. International Studies Quarterly 60:2, 230-242. [Crossref]

14. Mauro Rota. 2016. Military spending, fiscal capacity and the democracy puzzle. Explorations in Economic History 60, 41-51. [Crossref]

15. Alexandre Debs, Jessica Chen Weiss. 2016. Circumstances, Domestic Audiences, and Reputational Incentives in International Crisis Bargaining. Journal of Conflict Resolution 60:3, 403-433. [Crossref]

16. Eik Leong Swee. 2016. Economics of Civil War. Australian Economic Review 49:1, 105-111. [Crossref]

17. Dinissa Duvanova, Alexander Nikolaev, Alex Nikolsko-Rzhevskyy, Alexander Semenov. 2016. Violent conflict and online segregation: An analysis of social network communication across Ukraine's regions. Journal of Comparative Economics 44:1, 163-181. [Crossref]

18. Matthew O. Jackson, Stephen Nei. 2015. Networks of military alliances, wars, and international trade. Proceedings of the National Academy of Sciences 112:50, 15277-15284. [Crossref]

19. Sidartha Gordon, Alessandro Riboni. 2015. Doubts and Dogmatism in Conflict Behaviour. The Economic Journal 125:589, 1790-1817. [Crossref]

20. Massimo Morelli, Dominic Rohner. 2015. Resource concentration and civil wars. Journal of Development Economics 117, 32-47. [Crossref] 
21. Nicola Gennaioli, Hans-Joachim Voth. 2015. State Capacity and Military Conflict. The Review of Economic Studies 82:4, 1409-1448. [Crossref]

22. Mila Kashcheeva, Kevin K. Tsui. 2015. Political oil import diversification by financial and commercial traders. Energy Policy 82, 289-297. [Crossref]

23. George Tridimas. 2015. War, disenfranchisement and the fall of the ancient Athenian democracy. European Journal of Political Economy 38, 102-117. [Crossref]

24. Iain W. Long. 2015. Better feared than loved: Reputations and the motives for conflict. Journal of Economic Behavior \& Organization 114, 46-61. [Crossref]

25. Philip T. Hoffman. 2015. What Do States Do? Politics and Economic History. The Journal of Economic History 75:02, 303-332. [Crossref]

26. Jörg Franke, Tahir Öztürk. 2015. Conflict networks. Journal of Public Economics 126, 104-113. [Crossref]

27. Avidit Acharya, Edoardo Grillo. 2015. War with Crazy Types. Political Science Research and Methods 3:02, 281-307. [Crossref]

28. Jennifer Brauner. 2015. Military spending and democracy. Defence and Peace Economics 1-15. [Crossref]

29. Eyal Pecht, Asher Tishler. 2015. The value of military intelligence. Defence and Peace Economics 26:2, 179-211. [Crossref]

30. Francesco Caselli, Massimo Morelli, Dominic Rohner. 2015. The Geography of Interstate Resource Wars *. The Quarterly Journal of Economics 130:1, 267-315. [Crossref]

31. Philip Arena, Nicholas P. Nicoletti. 2014. Selectorate theory, the democratic peace, and public goods provision. International Theory 6:03, 391-416. [Crossref]

32. Hadas Shabtay, Asher Tishler. 2014. Budget allocation under uncertainty and the costs of war and insecurity. Defence and Peace Economics 25:5, 461-480. [Crossref]

33. Paola Conconi, Nicolas Sahuguet, Maurizio Zanardi. 2014. DEMOCRATIC PEACE AND ELECTORAL ACCOUNTABILITY. Journal of the European Economic Association 12:4, 997-1028. [Crossref]

34. Stefano DellaVigna, Ruben Enikolopov, Vera Mironova, Maria Petrova, Ekaterina Zhuravskaya. 2014. Cross-Border Media and Nationalism: Evidence from Serbian Radio in Croatia. American Economic Journal: Applied Economics 6:3, 103-132. [Abstract] [View PDF article] [PDF with links]

35. S. Zeigler, J. H. Pierskalla, S. Mazumder. 2014. War and the Reelection Motive: Examining the Effect of Term Limits. Journal of Conflict Resolution 58:4, 658-684. [Crossref]

36. Facundo Albornoz, Esther Hauk. 2014. Civil War and U.S. Foreign Influence. Journal of Development Economics . [Crossref]

37. Luis C. Corchón, Anıl Yildizparlak. 2013. Give peace a chance: The effect of ownership and asymmetric information on peace. Journal of Economic Bebavior \& Organization 92, 116-126. [Crossref]

38. D. Rohner, M. Thoenig, F. Zilibotti. 2013. War Signals: A Theory of Trade, Trust, and Conflict. The Review of Economic Studies 80:3, 1114-1147. [Crossref]

39. PHILIP T. HOFFMAN. 2012. Why Was It Europeans Who Conquered the World?. The Journal of Economic History 72:03, 601-633. [Crossref]

40. Patrick L. Warren. 2012. Volunteer Militaries, The Draft, and Support for War. Economics \& Politics $\mathrm{n} / \mathrm{a}-\mathrm{n} / \mathrm{a}$. [Crossref]

41. Clara Ponsati, Santiago Sanchez-Pages. 2012. Optimism and commitment: an elementary theory of bargaining and war. SERIEs 3:1-2, 157-179. [Crossref] 
42. MARK HARRISON, NIKOLAUS WOLF. 2011. The frequency of wars1. The Economic History Review no-no. [Crossref]

43. Vincent Vicard. 2011. Trade, conflict, and political integration: Explaining the heterogeneity of regional trade agreements. European Economic Review . [Crossref]

44. S. Baliga, D. O. Lucca, T. Sjostrom. 2011. Domestic Political Survival and International Conflict: Is Democracy Good for Peace?. The Review of Economic Studies 78:2, 458-486. [Crossref]

45. Charles Anderton. 2010. CHOOSING GENOCIDE: ECONOMIC PERSPECTIVES ON THE DISTURBING RATIONALITY OF RACE MURDER. Defence and Peace Economics 21:5, 459-486. [Crossref]

46. ALEXANDRE DEBS, H.E. GOEMANS. 2010. Regime Type, the Fate of Leaders, and War. American Political Science Review 104:03, 430-445. [Crossref]

47. Stefan Brandauer, Florian Englmaier. 2009. A model of strategic delegation in contests between groups. Review of Economic Design 13:3, 205-232. [Crossref]

48. Benjamin F Jones, Benjamin A Olken. 2009. Hit or Miss? The Effect of Assassinations on Institutions and War. American Economic Journal: Macroeconomics 1:2, 55-87. [Crossref]

49. Thomas P. Tangerås. 2009. Democracy, autocracy and the likelihood of international conflict. Economics of Governance 10:2, 99-117. [Crossref]

50. Thomas P. Tangerås, Nils-Petter Lagerlöf. 2009. Ethnic Diversity, Civil War and Redistribution. Scandinavian Journal of Economics 111:1, 1-27. [Crossref]

51. Bruce M. Russett. 2009. Democracy, War and Expansion through Historical Lenses. European Journal of International Relations 15:1, 9-36. [Crossref] 